\title{
Pemanfaatan Satelit Himawari-8 Untuk Estimasi Curah Hujan Dengan Metode Convective Stratiform Technique (CST) Dan Modified Convective Stratiform Technique (Mcst) Di Wilayah Ekuatorial Dan Monsunal (Studi Kasus Sulawesi 2020)
}

\author{
Nur Habib Muzaki ${ }^{(1)}$, Eriska Febriati ${ }^{(2)}$, Yosafat Donni Haryanto ${ }^{(3)}$ \\ Sekolah Tinggi Meteorologi Klimatologi dan Geofisika \\ Jl. Perhubungan 1 No. 5 Komplek Meteorologi, Pondok Betung, Bintaro 15221, Indonesia. \\ e-mail: nur.habib.muzaki@stmkg.ac.id
}

\begin{abstract}
ABSTRAK
Curah hujan merupakan salah satu parameter cuaca yang sangat penting bagi kehidupan. Informasi data curah hujan mampu menunjukan pola tipe curah hujan si suatu wilayah. Kurangnya rapat persebaran alat pengamatan curah hujan menyebabkan cakupan wilayah menjadi sempit. Oleh karena itu, pemanfaatan metode estimasi curah hujan dengan menggunakan data satelit merupakan salah satu solusi untuk mendapatkan data curah hujan di wilayah yang tidak memiliki alat pengamatan curah hujan. Dalam penelitian ini, estimasi curah menggunakan data satelit Himawari-8 dengan menggunakan metode Convective Startiform Technique (CST) dan Modified Convective Startiform Technique (mCST). Metode CST meruapakan metode yang memisahkan komponen awan konvektif dan stratiform, sedangkan metode mCST merupakan metode modifikasi intensitas curah hujan serta luasan area rata-rata yang dilingkupi piksel terhadap metode CST. Penelitian ini dilakukan di wilayah tipe hujan ekuatorial yang diwakili oleh Kabupaten Luwu Utara dan wilayah tipe hujan monsunal yang diwakili oleh Kota Makassar. Penelitian ini dilakukan selama satu tahu dengan mengambil sampel bulan puncak curah hujan di kedua wilayah. Tujuan penelitian ini adalah untuk membandingkan kualitas hasil estimasi curah hujan dengan menggunakan metode CST dan metode mCST Berdasarkan hasil estimasi curah hujan, metode CST menghasilkan nilai yang lebih baik dibandingkan dengan metode mCST di kedua wilayah yang ditandai dengan nilai korelasi yang lebih baik. Nilai eror RMSE berkisar $33.80 \mathrm{~mm} / \mathrm{jam}$ hingga $42.66 \mathrm{~mm} / \mathrm{jam}$ dan Nilai MAE berkisar $26.30 \mathrm{~mm} / \mathrm{jam}$ hingga $34.55 \mathrm{~mm} / \mathrm{jam}$. Berdasarkan penelitian ini, kedua metode estimasi curah hujan ini, kurang mampu mempresentasikan data curah hujan di kedua wilayah.
\end{abstract}

Kata kunci : Estimasi curah hujan, Himawari-8, CST, mCST.

\section{ABSTRACT}

Rainfall is one of the most important weather parameters for life. Rainfall data information is able to show the pattern of rainfall types in an area. The lack of a meeting of the distribution of rainfall observation instruments has resulted in a narrow coverage area. Therefore, the use of rainfall estimation methods using satellite data is one solution to obtain rainfall data in areas that do not have rainfall observation tools. In this study, the bulk estimation used Himawari-8 satellite data using the Convective Startiform Technique (CST) method and the Modified Convective Startiform Technique ( $m C S T$ ). The CST method is a method that separates the convective and stratiform cloud components, while the mCST method is a method of modifying rainfall intensity and the average area area covered by pixels to the CST method. This research was conducted in the equatorial rain type area represented by North Luwu Regency and the monsoon rain type area represented by Makassar City. This research was conducted for one year by taking samples of the peak months of rainfall in both regions. The purpose of this study was to compare the quality of the estimation results of rainfall using the CST method and the mCST method. Based on the results of rainfall estimation, the CST method produced better values compared to the mCST method in both regions which were characterized by better correlation values. RMSE error values range from $22.80 \mathrm{~mm} / \mathrm{hour}$ to $42.66 \mathrm{~mm} /$ hour and MAE values range from $26.30 \mathrm{~mm} /$ hour to $34.55 \mathrm{~mm} / \mathrm{hour}$. Based on this research, these two rainfall estimation methods are not able to present rainfall data in the two regions.

Keywords : Rainfall estimation, Himawari-8, CST, mCST.

Nur Habib Muzaki ${ }^{1}$, Eriska Febriati ${ }^{2}$, Yosafat Donni Haryanto ${ }^{3 /}$

J Statistika Vol. 14, No. 2, (2021) 


\section{PENDAHULUAN}

Indonesia merupakan salah satu wilayah tropis dengan intensitas curah hujan yang tinggi. Hal ini disebabkan adanya banyaknya interaksi sirkulasi udara baik dalam skala lokal, regional, dan gelobal (Hasanah dkk., 2017). Data curah hujan di manfaatkan untuk mengetahui pola curah hujan di suatu wilayah unutk mengetahui kapan terjadinya awal musim hujan, awal musim kemarau serta puncak musim hujan untuk mengantisipasi bencana seperti kekeringan dan banjir.

Data curah hujan umumnya didapatkan melalui pengamatan langsung secara konvensional dengan menakar curah hujan menggunakan alat pengukur hujan. Akan tetapi, alat pengukur hujan yang hanya tersebar di beberapa wilayah dengan sebaran yang kurang rapat sehingga hanya bisa mencakup wilayah yang sempit (Danamik dkk., 2018). Sehingga menyebabkan tidak tersedianya data curah hujan di beberapa wilayah yang tidak memiliki alat pengukur hujan. Oleh karena itu, dibutuhkan metode estimasi curah hujan untuk mengatasi masalah tersebut. Pemanfaatan alat pengindraan jauh seperti satelit diharapkan sebagai solusi terhadap tidak tersedianya data curah hujan di beberapa wilayah (Krisnayanti dkk., 2020). Salah satu satelit cuaca yang sering digunakan adalah satelit Himawari- 8.

Salah satu metode estimasi curah hujan yang memanfaatkan data satelit cuaca berupa kanal Infrared (IR) dengan berdasarkan suhu puncak awan adalah Convective Startiform Technique (CST) dan Modified Convective Startiform Technique (mCST). Metode Convective Startiform Technique (CST) merupakan metode estimasi curah hujan dengan memanfaatkan suhu kecerahan awan untuk memisahkan awan konvektif dan stratiform yang di temukan oleh Alder dan Negri (1998), sedangkan Metode Modified Convective Startiform Technique (mCST) merupakan metode modifikasi intensitas curah hujan serta luasan area rata-rata yang dilingkupi piksel (Endarwin, 2014). Dalam penelitian yang dilakukan di wilayah Pontianak bahwa kedua metode Convective Startiform Technique (CST) dan Modified Convective Startiform Technique (mCST) memiliki hasil estimasi curah hujan per jam dengan kualitas yang baik serta korelasi yang kuat (Andani dan Endarwin, 2016). Kemudian dalan penelitian di wilayah Pontianak sebagai wilayah dengan tipe curah hujan ekuatorial serta di wilayah Surabaya sebagai wilayah dengan tipe curah hujan monsunal bahwa metode Convective Startiform Technique (CST) dan Modified Convective Startiform Technique (mCST) memiliki kemampuan yang cukup baik unutk estimasi curah hujan ringan dan sangat lebat (Andani dan Putra, 2016).

Dalam penelitian ini, metode Convective Startiform Technique (CST) dan Modified Convective Startiform Technique (mCST) digunakan dalam estimasi curah hujan pada tahun 2020 di pulau Sulawesi dengan wilayah yang memiliki tipe curah hujan ekuatorial dan monsunal. Untuk wilayah dengan tipe curah hujan ekuatorial yang memiliki dua puncak hujan dalam setahun diwakili oleh Kabupaten Luwu Utara dan tipe curah hujan monsunal diwakili oleh wilayah Kota Makassar. Tujuan penelitian ini adalah untuk menganalisis dan membandingkan kualitas hasil estimasi curah hujan dari metode Convective Startiform Technique (CST) dan Modified Convective Startiform Technique (mCST).

\section{METODE PENELITIAN}

\subsection{Lokasi penelitian}

Penelitian ini dilakukan di Kabupaten Luwu Utara yang memiliki koordinat $20^{\circ} 30^{\prime}$ sampai $2^{\circ} 37$ Lintang Selatan dan $119^{\circ} 41^{\prime}$ sampai $12^{\circ} 43^{\prime}$ Bujur Timur dan Kota Makassar dengan koordinat $5^{\circ} 30^{\prime}$ hingga $5^{\circ} 14^{\prime}$ Lintang Selatan dan $19^{\circ} 18^{\prime}$ hingga $119^{\circ} 32^{\prime}$ Bujur Timur seperti yang digambarkan pada Gambar 1

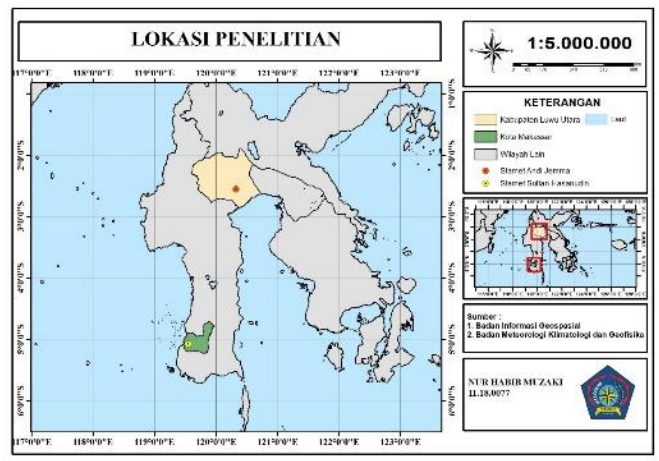

Gambar 1. Peta wilayah penelitian.

\subsection{Data Penelitian}

Data yang digunakaan dalam penelitian ini adalah data pengamatan curah hujan bulanan dan setiap satu jam selama satu tahun pada 2020 di Staisun Meteorologi kelas III Andi Jemma dan Stasiun Meteorologi Kelas I Sultan Hasanuddin, serta data satelit Himawari-8 kanal 13 atau kanal Infrared Enhance (IR) yang diperoleh dari ftp://satelit.bmkg.go.id dalam format netCDF (.nc) setiap satu jam pada bulan Juni dan Desember pada tahun 2020. 


\subsection{Metode Penelitian}

Dalam penelitian ini, metode yang digunakan untuk estimasi curah hujan adalah metode Convective Startiform Technique (CST) dan Modified Convective Startiform Technique (mCST). Data yang sudah ada di olah menggunakan Microsoft Excel serta Google Colab. Adapun pengolahan data adalah sebagai berikut:

1. Mengunpulkan dan mengolah dalam Microsoft Excel data curah hujan bulanan sepanjang tahun 2020 di wilayah Kabupaten Luwu Utara dan Kota Makassar dalam bentuk garfik untuk melihat bulan puncak curah hujan.

2. Mengatur waktu dan koordinat lokasi penelitian

3. Konversi Data

Data satelit Himawari-8 kanal Infrared Enhance (IR) setiap satu jam dalam bulan puncak hujan di konversi dalam ekstensi file NetcCDF (.nc) sehingga diperoleh temperatur kecerahan awan $\left(\mathrm{T}_{\mathrm{BB}}\right)$ atau $\mathrm{T}$ minimum dalam satu atau multi piksel.

4. Penentuan Inti Konvektif

Setelah melakukan identifikasi terhadap suhu kecarahan awan $\left(\mathrm{T}_{\mathrm{BB}}\right)$, dilakukan pengukuran kekuatan awan konvektif dengan memperhitungkan slope parameter (S) (Alder dan negri, 1988).

5. Pemisahan Awan Konvektif dan Stratiform

Pemisahan awan konvektif dan stratiform ini dilakukan dengan menggunakan data satelit Himawari-8 kanal Infrared dengan mencari slope parameter (S) dengan menggunakan rumus (Islam dkk., 2002; Endarwin, 2014):

$S=k\left(T_{\mathrm{i}}-1, j-1+T_{\mathrm{i}}-1, j+T_{\mathrm{i}}+1, j+1+\right.$

$T_{\mathrm{i}}+1, j+T_{\mathrm{i}, j}-1+\quad T_{\mathrm{i}, j} \quad+1+T_{\mathrm{i}}+1, j-1 \quad+$

$\left.T_{\mathrm{i}}-1, j+1-8 T_{\mathrm{i}, j}\right)$

Keterangan:

$\mathrm{S}=$ slope parameter $(\mathrm{S})(\mathrm{K})$

$\mathrm{i}$ dan $\mathrm{j}=$ posisi nilai piksel dimana $\mathrm{S}$ dihitung

$\mathrm{T}=$ temperatur kecerahan awan $\left(\mathrm{T}_{\mathrm{BB}}\right)(\mathrm{K})$

$\mathrm{K}=$ konstanta $(0.125)$

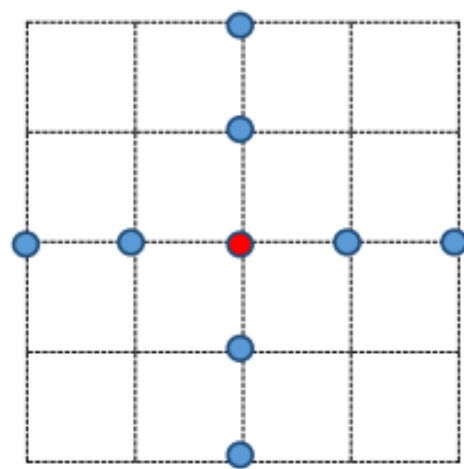

Gambar 2. Lokasi 8 titik penentuan slope parameter.

Untuk pemisahan awan konvektif dan stratiform dilakukan dengan pembatasan yang menggunakan persamaan (Islam dkk, 2002; Endarwin, 2014):

$$
S \geq \exp \left[0.0826\left(T_{\min }-207\right)\right]
$$

Keterangan

$\mathrm{T}_{\min }=$ temperature minimum relatif dari $\mathrm{T}_{\mathrm{BB}}$ (K)

Dalam penelitian ini, dilakikan pemilihan satu piksel sebagai perwakilan koordinat stasiun, sehingga data $\mathrm{T}_{\min }$ meruapakan temperatur pada piksel tersebut. Apabila nilai slope parameter (S) memenuhi persamaan 2 maka merupakan inti awan konvektif dan sebaliknya (Islam dkk., 2002).

6. Penentuan luasan wilayah konvektif dan stratiform

Penentuan luasan wilayah konvektif dan stratiform ditentukan dengan menggunakan persamaan (Islam dkk., 2002; Endarwin, 2014). Untuk luasan awan konvektif ditentukan menggunakan rumus sebagi berikut:

$$
\ln \left(A_{\mathrm{c}}\right)=a T_{\mathrm{ci}}+\mathrm{b}
$$

Keterangan:

$\mathrm{A}_{\mathrm{c}}=$ luasan area hujan konvektif $\left(\mathrm{km}^{2}\right)$

$\mathrm{T}_{\mathrm{ci}}=$ temperatur puncak awan pada inti

konvektif ke-i (K)

$\mathrm{a}=-0.0492$

$\mathrm{b}=15.27$

Sedangkan utnuk luasan awan stratiform ditentukan dengan menggunakan rumus sebagai berikut:

$$
\ln \left(A_{\mathrm{s}}\right)=a T_{\mathrm{s}}+\mathrm{b}
$$

Keterangan:

$\mathrm{A}_{\mathrm{S}} \quad=$ luasan area hujan stratiform $\left(\mathrm{km}^{2}\right)$

$\mathrm{T}_{\mathrm{S}} \quad=$ temperatur puncak awan stratiform $(\mathrm{K})$

Dalam penelitian ini, hanya dipilih satu piksel yang mewakili koordinat stasiun, maka $\mathrm{T}_{\min }$ untuk $\mathrm{T}_{\mathrm{ci}}$ dan $\mathrm{T}_{\mathrm{s}}$ merupakan sebagai temperatur kecerahan awan pada piksel yang dibaca dalam penentuan $T_{\text {s }}$.

Nur Habib Muzaki ${ }^{1}$, Eriska Febriati ${ }^{2}$, Yosafat Donni Haryanto ${ }^{3 /}$

J Statistika Vol. 14, No. 2, (2021) 
7. Tahapan estimasi curah hujan setiap jamEstimasi curah hujan dengan menggunakan metode Convective Startiform Technique (CST) menggunakan persamaan sebagai berikut (Islam dkk., 2002; Endarwin, 2014):

Curah Hujan Stratiform $(\mathrm{mm})=\mathrm{C}\left(\mathrm{A}_{\mathrm{C}} / \mathrm{A}\right) \mathrm{TR}_{\mathrm{c}}$

Keterangan:

$\mathrm{C}$ = baingan sel konvektif

$\mathrm{A}_{\mathrm{c}}=$ luasan area hujan konvektif $\left(\mathrm{km}^{2}\right)$

A $=$ rata-rata area yang dilingkup piksel $\left(\mathrm{km}^{2}\right)$

$\mathrm{T} \quad=$ rata-rata periode estimasi (jam)

$\mathrm{R}_{\mathrm{c}} \quad=$ intensitas curah hujan konvektif (mm/jam)

Curah Hujan Stratiform $(\mathrm{mm})=\mathrm{S}_{\mathrm{t}}\left(\mathrm{A}_{\mathrm{s}} / \mathrm{A}\right) \mathrm{TR}_{\mathrm{s}}$

Keterangan:

$\mathrm{S}_{\mathrm{t}} \quad=$ bilangan sel stratiform

$\mathrm{A}_{\mathrm{s}} \quad=$ luasan area hujan stratiform $\left(\mathrm{km}^{2}\right)$

A = rata-rata area yang dilingkup piksel $\left(\mathrm{km}^{2}\right)$

$\mathrm{T}=$ rata-rata periode estimasi (jam)

$\mathbf{R}_{\mathrm{s}} \quad=$ intensitas curah hujan stratiform $(\mathrm{mm} / \mathrm{jam})$

Nilai $\mathrm{T}$ adalah 1, dikarenakan estimasi curah hujan dilakukan untuk curah hujan setiap jam serta nilai C dan $S_{t}$ juga adalah 1 karena pada penlitian ini hanya merujuk pada titik tertentu yang dipilih. Perbedaan spesifikasi metode Convective Startiform Technique (CST) dan Modified Convective Startiform Technique (mCST) yang digunanakan dapat dilihat pada table table 1 .

Tabel 1. Perbedaan spesifikasi metode CST dan mCST.

\begin{tabular}{|c|c|c|c|}
\hline \multirow{2}{*}{ Metode } & \multicolumn{2}{|c|}{ Intensitas Curah Hujan (mm/jam) } & $\begin{array}{c}\text { Luasan Rata-Rata } \\
\text { nyea Yang Dilingkupi }\end{array}$ \\
\cline { 2 - 3 } CST & Konvektif (Rc) & Stratiform (Rs) & 121 \\
\hline Mcst & 20 & 3.5 & 202.1243 \\
\hline
\end{tabular}

8. Verifikasi hasil estimasi curah hujan

Verifikasi hasil estimasi curah hujan dilakukan dengan data pengamatan curah hujan dari stasiun yang telah dipilih. Verifikasi dilakukan untuk melihat bagus atau tidak nya kedua metode tersebut terhadapa hasil data pengukuran curah hujan observasi. Menurut Pahlevi (2016) verifikasi hasil estimasi curah hujan terhadap curah hujan observasi dapat dilakukan dengan perhitungan sebagai berikut:

a. Koefisien Korelasi (C)

Korelasi merupakan salah satu metode statistik yang digunakan untuk mengetahui menguji ada atau tidaknya hubungan antar variabel, sedangkan koefisien korelasi (C) adalah bilangan yang menyatakan besar kecilnya suatu hubungan (Pahlevi, 2016).

$$
C=\frac{\sum_{i=1}^{n}\left(R O_{i}-\overline{R O}\right)\left(R E_{i}-\overline{R E}\right)}{\sqrt{\sum_{i=1}^{n}\left(R O_{i}-\overline{R O}\right)^{2}} \sqrt{\sum_{i=1}^{n}\left(R E_{i}-\overline{R E}\right)^{2}}}
$$

Tabel 2. Kategori koefesien korelasi.

\begin{tabular}{|c|c|}
\hline Interval Korelasi & Tingkat Hubungan \\
\hline $0.00-0.199$ & Sangat Lemah \\
\hline $0.20-0.399$ & Lemah \\
\hline $0.40-0.599$ & Sedang \\
\hline $0.60-0.799$ & Kuat \\
\hline $0.80-1.000$ & Sangat Kuat \\
\hline
\end{tabular}

b. Root Mean Square Eror (RMSE)

RMSE digunakan untuk mengetahui besarnya penyimpangan yang terjadi antara data curah hujan hasil estimasi dengan dat curah hujan hasil pengamatan atau observasi (Rizki, 2020).

$$
R M S E=\sqrt{\frac{\sum_{i=1}^{n}\left(R E_{i}-R O_{i}\right)^{2}}{n}}
$$

c. Mean Absolute Eror (MAE)

Mean Absolute Eror (MAE) adalah rata-rata absolut dari kesalahan estimasi, tanpa menghiraukan tanda positif atau negatif.

$M A E=\frac{1}{n} \sum_{i=1}^{n}\left|\left(R E_{i}-R O_{i}\right)\right|$

Keterangan:

$\mathrm{RE}_{\mathrm{i}}$ dan $\mathrm{RO}_{\mathrm{i}} \quad=$ nilai estimasi curah hujan dan observasi ke-i

$\overline{\mathrm{RE}}$ dan $\overline{\mathrm{RO}}=$ nilai rata-rata estimasi dan observasi

$\mathrm{n} \quad=$ jumlah data

\section{HASIL DAN PEMBAHASAN}

3.1. Penentuan Puncak Curah Hujan

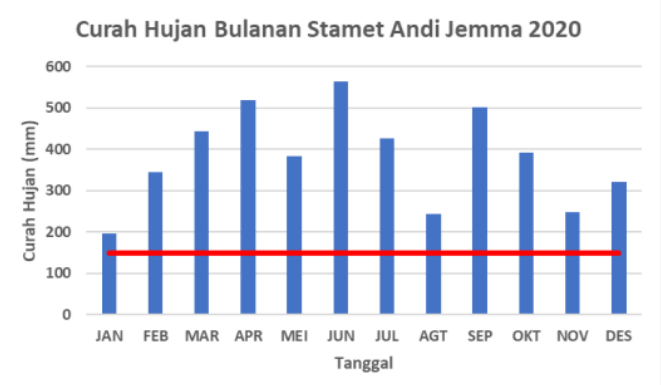

Gambar 3. Curah hujan bulanan Stasiun Meteorologi Andi Jemma 2020. 
Berdasarkan Gambar 3, menunjukkan curah hujan bulanan stasiun meteorologi Andi Jemma pada tahun 2020. Terlihat bahwa puncak curah hujan terjadi pada bulan Juni sebesar $563.6 \mathrm{~mm}$.

Curah Hujan Bulanan Stamet Sultan Hasanudin 2020

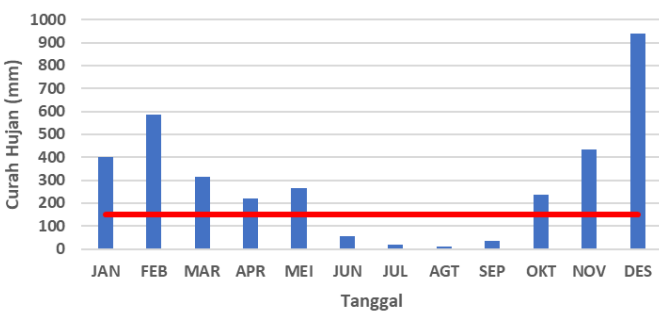

Gambar 4. Curah hujan bulanan Stasiun Meteorologi Sultan Hasanudin 2020.

Berdasarkan Gambar 4, menunjukan curah hujan bulanan pada Stasiun Meteorologi Sultan Hasanudin pada tahun 2020. Terlihat bahwa puncak curah hujan terjadi pada bulan Desember sebesar 939.1 mm.

\subsection{Estimasi Curah dengan Metode Convective Startiform Technique (CST)}

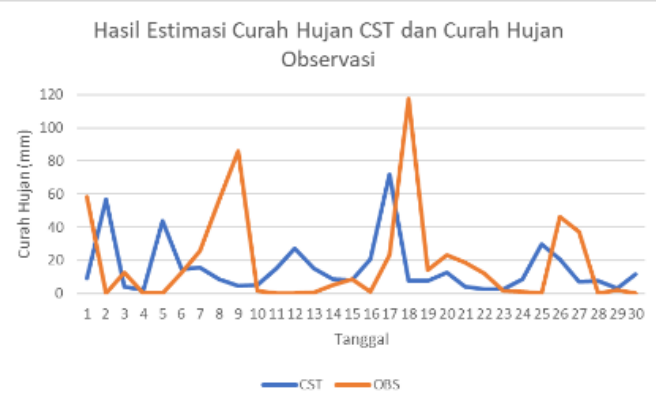

Gambar 5. Hasil estimasi curah hujan CST dan curah hujan observasi di Stasiun Meterologi Andi Jemma.

Berdasarkan Gambar 5, terlihat nilai estimasi curah hujan dengan metode Convective Startiform Technique (CST) di Kabupaten Luwu Utara, dengan menghasilkan estimasi curah hujan harian dengan nilai yang lebih rendah dibandingkan dengan data observasi, dengan selisih yang cukup tinggi. Data hasil estimasi curah hujan kurang baik dalam mempresentasikan curah hujan yang rendah di Kabupaten Luwu Utara.

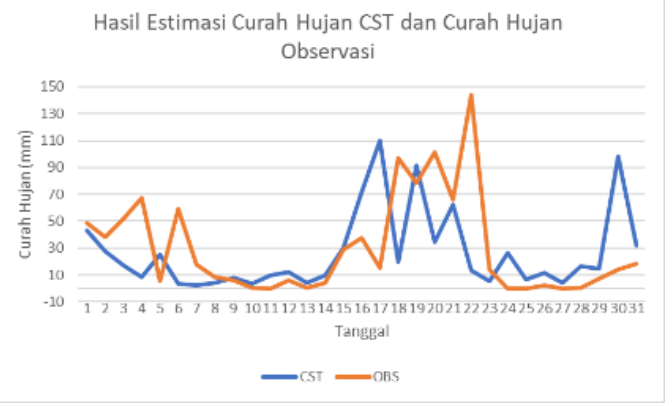

Gambar 6. Hasil estimasi curah hujan CST dan curah hujan observasi di Stasiun Meteorologi Sultan Hasanudin.

Berdasarkan Gambar 6, terlihat nilai estimasi curah hujan dengan metode Convective Startiform Technique (CST) di Kota Makassar, dengan menghasilkan estimasi curah hujan harian yang mampu mengikuti pola curah hujan dengan intensitas tinggi dari hasil data curah hujan observasi. Beberapa data hasil estimasi curah hujan juga dapat mendekati nilai curah hujan observasi.

\subsection{Estimasi Curah Hujan dengan Metode Modified Convective Startiform Technique (mCST)}

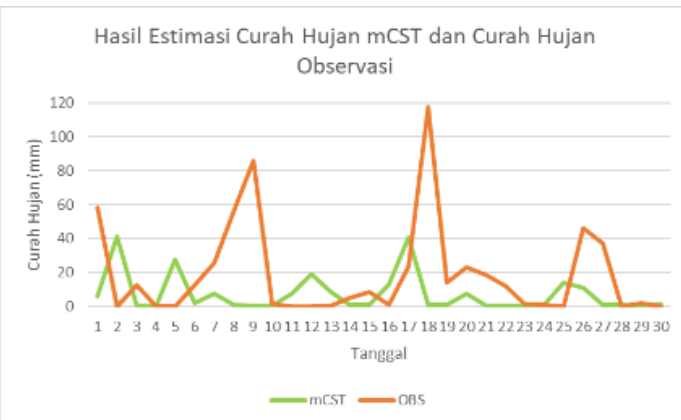

Gambar 7. Hasil estimasi curah hujan mCST dan curah hujan observasi di Stasiun Meterologi Andi Jemma.

Berdasarkan Gambar 7, terlihat nilai estimasi curah hujan dengan menggunakan metode Modified Convective Startiform Technique (mCST) di Kabupaten Luwu Utara. Pola estimasi curah hujan dengan metode mCST sangat berbeda dengan pola yang dihasilkan dari data curah hujan observasi. Nilai estimasi curah hujan yang berada di bawah nilai curah hujan observasi dengan selisih yang cukup besar. 


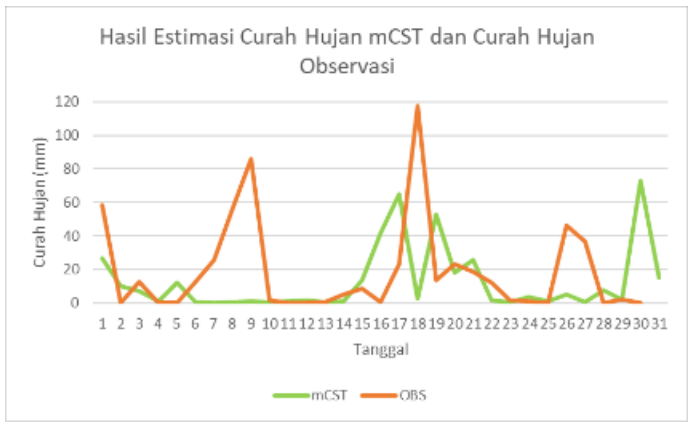

Gambar 8. Hasil estimasi curah hujan mCST dan curah hujan observasi di Stasiun Meteorologi

Sultan Hasanudin

Berdasarkan Gambar 8, terlihat nilai estimasi curah hujan dengan menggunakan metode Modified Convective Startiform Technique (mCST) di Kota Makassar. Pola estimasi curah hujan dengan metode mCST cukup baik dalam mempresentasikan curah hujan dalam intensitas yang rendah dengan selisih yang tidak terlalu besar. Akan tetapi tidak cukup baik dalam mempresentasikan data curah hujan observasi dalam intensitas yang tinggi, ditandai dengan besarnya selisih hasil data estimasi dan data observasi.

\subsection{Verifikasi Hasil Estimasi Curah Hujan dengan Data Observasi}

Tabel 3. Verifikasi data curah hujan hasil estimasi dengan data observasi.

\begin{tabular}{|c|c|c|c|}
\hline & CST & mCST & Wilayah \\
\hline Korelasi & -0.15 & -0.17 & \multirow{2}{*}{ Luwu Utara } \\
\hline RMSE & 34.55 & 33.80 & \\
\hline MAE & 23.27 & 21.46 & \\
\hline Korelasi & 0.19 & 0.13 & \multirow{2}{*}{ Makassar } \\
\hline RMSE & 42.17 & 42.66 & \\
\hline MAE & 26.93 & 26.30 & \\
\hline
\end{tabular}

Berdasarkan Tabel 3, menunjukkan bahwa metode Convective Startiform Technique (CST) lebih baik dibandingkan dengan metode Modified Convective Startiform Technique (mCST) dengan nilai korelasi yang lebih besar yang menunjukkan bahwa curah hujan hasil metode Convective Startiform Technique (CST) lebih mendekati terhadap curah hujan hasil observasi. Nilai korelasi di Kota Makassar lebih besar dibandingkan dengan nilai korelasi di Kabupaten Luwu Utara yang menunjukkan bahwa metode Convective Startiform Technique (CST) di Kota Makassar lebih mendekati hasil observasi. Kemudian berdasarkan nilai RMSE, menunjukkan bahwa hasil kedua metode baik metode Convective Startiform Technique (CST) dan Modified Convective Startiform Technique (mCST) memiliki penyimpangan atau error yang besar terhadap data observasi curah hujan, yaitu 33.8 nilai MAE atau nilai rata-rata sebesar $21.46 \mathrm{~mm} / \mathrm{jam}$ hingga 26.30 $\mathrm{mm} / \mathrm{jam}$ yang menunjukkan bahwa rata-rata penyimpangan estimasi curah hujan cukup besar dari kedua metode terhadap curah hujan observasi.

\section{KESIMPULAN DAN SARAN}

Berdasarkan hasil estimasi curah hujan setiap jam dengan metode Convective Startiform Technique (CST) dan Modified Convective Startiform Technique (mCST) di wilayah dengan tipe curah hujan ekuatorial yang diwakili oleh Kabupaten Luwu Utara serta wilayah dengan tipe curah hujan monsunal yang diwakili oleh Kota Makassar diperoleh kesimpulan sebagai berikut:

1. Metode estimasi curah hujan Convective Startiform Technique (CST) menghasilkan estimasi curah hujan yang lebih dibandingkan metode Modified Convective Startiform Technique (mCST) di kedua wilayah.

2. Hasil estimasi curah hujan dari kedua metode di Kota Makassar memiliki estimasi yang lebih mendekati curah hujan hasil observasi dibandingkan dengan di Kabupaten Luwu Utara yang dapat dilihat dengan nilai korelasi yang lebih besar di Kota Makassar sebesar -0.15 hingga 0.19.

3. Berdasarkan hasil verifikasi estimasi curah hujan dan data observasi, bahwa estimasi curah hujan dengan metode Convective Startiform Technique (CST) dan Modified Convective Startiform Technique (mCST) ini menghasilkan penyimpangan yang besar terhadap curah hujan hasil observasi, yaitu sebesar $33.80 \mathrm{~mm} / \mathrm{jam}$ hingga $42.66 \mathrm{~mm} / \mathrm{jam}$. Sehingga, kedua metode ini tidak cocok digunakan untuk estimasi curah hujan di Kota Makassar dan Kabupaten Luwu Utara.

\section{DAFTAR PUSTAKA}

Andani, A.J.P. dan Endarwin., (2016). Kajian Penerapan Estimasi Curah Hujan Per Jam Memanfaatkan Metode Convection Stratiform Technique (CST) dan Modified Convective Stratiform Technique (mCST) di Pontianak. Jurnal Meteorologi Klimatologi dan Geofisika, 3(3), 9-20.

Andani, A.J.P. dan Putra, R.M. (2016). Penerapan Curah Hujan dengan Metode CST dan MCST di Wilayah Tipe Curah hujan Ekuatorial dan Monsunal (Studi kasus Pontianak, November 2014 dan Surabaya, 
J Statistika Vol. 14, No. 2, (2021), Hal. 67-73

Januari 2014). Prosiding Seminar Hari Meteorologi Dunia

Danamik R.A., Dewi, N.K.T., Wulandari, A.V., Fadlan,, A., 2018. Penggunaan Metode Modified Convective Stratiform Technique (mCST) di Wilayah Tipe Curah Hujan Ekuatorial, Monsunal dan Lokal. Seminar Nasional Penginderaan Jauh.

Endarwin, 2014, Modifikasi Convective Stratiform Technique dengan Kombinasi Data Satelit Gelombang Mikro Pasif dan Inframerah untuk Estimasi Curah Hujan di Indonesia, Disertasi, Program Studi Sains Kebumian, Institut Teknologi Bandung, Bandung

Hasanah, N., Ugiarto, M., dan Puspitasari, N., 2017, Sistem Pengelompokan Curah Hujan Menggunakan Metode K-Means Di wilayah Kalimantan Timur, Prosiding Seminar Nasional Ilmu Komputer dan Teknologi Informasi, Vol. 2. No. 2.

Islam, M. N., Islam, A. K. M. S., Hayashi, T., Terao, T. dan Uyeda, H, 2002, Application of a Method to Estimate Rainfall in Bangladesh Using GMS- 5 Data, Journal of Natural Disaster Science, Vol. 24, no. 2 pp 83-89.

Jiang, S., Ren, L., Yong, B., Yang, X. dan Shi, L, 2010, Evaluation of High Resolution Satellite Precipitation Products with Surface Rain Gauge Observations from Laohahe Basin in Northern China. Water Science and Engineering, Vol. 3, no. 4 pp 405- 417.

Krisnayanti, D. S., Welkis, D. F. B., Hepy, F. M., dan Legono, D. 2020. Evaluasi Kesesuaian Data Tropical Rainfall Measuring Mission (TRMM) Dengan Data Pos Hujan Pada Das Temef Di Kabupaten Timor Tengah Selatan. Jurnal Sumber Daya Air, 16(1), 51-62.

Pahlevi, A. R., 2016. Skema Parameterisasi Kumulus Untuk Prediksi Hujan di Wilayah Bandar Lampung. Prosiding SNSA.
Rizki, M., Basuki, S., \& Azhar, Y. 2020. Implementasi Deep Learning Menggunakan Arsitektur Long Short Term Memory Untuk Prediksi Curah Hujan Kota Malang. Repositor, 2(3), 331-338. 